\title{
Metamalzeme Tabanlı Hassas Süt ve Sıvı Sensörü Uygulaması
}

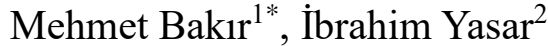 \\ ${ }^{1}$ Bozok Üniversitesi, Mühendislik Mimarlık Fakültesi, Bilgisayar Mühendisliği,Yozgat, Türkiye (ORCID: 0000-0002-5847-743X) \\ ${ }^{2}$ Bozok Üniversitesi, Fen Bilimleri Enstitüsü, Mekatronik Mühendisliği Anabilim Dalı, Yozgat, Türkiye
}

(Bu yayın 26-27 Haziran 2020 tarihinde HORA-2020 kongresinde sözlü olarak sunulmuştur.)

(DOI: 10.31590/ejosat.778770)

ATIF/REFERENCE: Bakır, M. \& Yasar, İ. (2020). Metamalzeme Tabanlı Hassas Süt ve Sıvı Sensörü Uygulaması. Avrupa Bilim ve Teknoloji Dergisi, (Special Issue), 10-16.

\begin{abstract}
$\ddot{\mathbf{O} z}$
Metamalzeme tabanlı sensör uygulamarı; günümüzde fiziksel parametrelerin tespiti, saflık analizlerinde, kanserli hücrelerin tespiti, gıda ve petrol ürünlerindeki hilelerin tespitinde aktif olarak kullanılmaktadır. Mevcut literatüre bakıldığında metamalzeme tabanlı sensörlerin süt üzerindeki çalışmasını gösteren, yağlı ve yağsız süt arasındaki çok düşük bir dielektrik katsayısı değişimini algılayabilecek metamalzeme tabanlı sensöre ihtiyaç duyulmaktadır. Bu durum ise algılama hassasiyeti ve kalite faktörü gibi sorunları ortaya çıkarmaktadır. Bu çalışma da bahsedilen sorunların çözümüne yönelik olarak 4 ayrık rezonatörden oluşan yapının tasarımı yapılmıştır. Bu yapı düşük dielektrik katsayısına sahip olan Arlon DiClad 527 malzemesinin hem ön hem de arka yüzlerine yerleştirilmiştir. Önerilen tasarımda ön ve arka yüzde yer alan rezonatörler $180^{\circ}$ farkla yerleştirilmiş̧ir. Rezonatör boyutları ve şekilleri ihtiyaç duyulan yüksek hassasiyet ve yüksek kalite faktörü değerlerini karşılayacak şekilde CST Microwave Studio programında tasarlanmış ve boyutları optimize edilmiştir. Yağlı ve yağsız sütün dielektrik katsayı ölçümleri için $85070 \mathrm{E}$ açık uçlu koaksiyel prob ve vektör network analizörü kullanılarak X bantta ölçülmüş ve her iki süte ait dielektrik katsayı değerlerinin sırasıyla 62 ve 58 olduğu tespit edilmiştir. Önerilen metamalzeme tasarımının arkasına yerleştirilen örnek tutucunun ve bu dielektrik değerleri kullanılarak tanımlanan yağlı ve yağsız süt verilerinin kullanılmasıyla Simülasyon çalışmaları yapılmıştır. Simülasyon çalışmaları sonucunda Her iki süt arasında, yapplan çalışmayla metamalzeme temelli sensörün $60 \mathrm{MHz}$ gibi yüksek bir frekans kayması ile yağlı ve yağsız süt arasındaki farkı algıllayabildiği görülmüş̧ür. Ayrıca metamalzeme temelli sensör çalışmalarının bir diğer gereksinimi olan yüksek kalite faktörünü de önerilen çalışma karşılamaktadır. Simülasyon sonuçlarına bakıldığında Q faktör değerinin 288 olduğu hesaplanmıştır. Bu değer pek çok sensör çalışmasının Q değerinden daha yüksektir. Önerilen yapının dielektrik katsayısının 40-80 değerleri arasında değişen tüm malzemelere rahatlıkla uygulanabileceği, hem deneysel hem de simülasyon sonuçlarının veri değerlerine dayanılarak tespit edilmiştir. Önerilen çalışmada yağlı ve yağsız süte ilişkin yüksek hassasiyet gerektiren bir çalışma bulunmaması, çalışmanın sahip olduğu yüksek kalite faktörü, daha önce ortaya atılmamış ve kullanılmamış olmasıyla tasarımın orijinal olduğu söylenebilir.
\end{abstract}

Anahtar Kelimeler: Metamalzeme, Sensör, Süt, Sıvı, Gıda

\section{Metamaterial Based High Sensitive Milk and Liquid Sensor Application}

\begin{abstract}
Metamaterial based sensor applications are actively used in the detection of physical parameters, in purity analysis, in the detection of cancerous cells, in the detection of fraud in food and petroleum products. Looking at the current literature, there is a need for a metamaterial-based sensor that can detect a very low dielectric coefficient change between fat and skim milk, showing the work of metamaterial-based sensors on milk. This raises problems such as sensing sensitivity and quality factor. In this study, the structure consisting of 4 different resonators was designed for the solution of the mentioned problems. This structure is placed on both the front and back sides of Arlon DiClad 527 material, which has a low dielectric coefficient. In the proposed design, the resonators located on
\end{abstract}

* Sorumlu Yazar: Yozgat Bozok Üniversitesi, Mühendislik Mimarlık Fakültesi, Bilgisayar Mühendisliği Bölümü, Yozgat, Türkiye, ORCID: 00000002-5847-743X, mehmet.bakir@yobu.edu.tr 
the front and back are placed by a margin of $180^{\circ}$. The dimensions and shapes of the resonator are designed and optimized in CST Microwave Studio program to meet the required high precision and high-quality factor values. For the dielectric coefficient measurements of oily and skimmed milk, the $85070 \mathrm{E}$ was measured in the X-band using an open-ended coaxial probe and vector network analyzer, and the dielectric coefficient values for these two milks were found to be 62 and 58 , respectively. Simulation studies have been carried out using the sample holder placed behind the proposed metamaterial design and the fat and skim milk data defined using these dielectric values. As a result of the simulation studies, it was seen that the metamaterial-based sensor can detect the difference between fat and skim milk with a high frequency shift like $60 \mathrm{MHz}$. In addition, the proposed study meets the high-quality factor, which is another requirement of metamaterial based sensor studies. Considering the simulation results, the Q factor value was calculated at 288. This value is higher than the $\mathrm{Q}$ value of many sensor operations. It has been determined based on the data values of both experimental and simulation results that the dielectric coefficient of the proposed structure can be easily applied to all materials ranging from 40-80. In the proposed study, it can be said that the design is totally unique by means of the absence of a high-precision study on fat and skimmed milk, the high quality factor of the study and the fact that it has not been previously revealed or used.

Keywords: Metamaterial, Sensor, Milk, Liquid, Food

\section{Giriş}

Bir malzemenin dielektrik katsayısı, çevresel faktörlere ve saflığa göre değişir. Değişen değer saflık, sıcaklık, nem ve malzemenin içeriği hakkında bize bir çok bilgi sunabilir. Bu bilgilerle mikrodalga frekanslarında doğada var olmayan ve negatif kırılma indisi gibi pek çok özelliği üzerinde barındıran metamalzemeler kullanılarak farklı alanlarda kullanılmak üzere çeşitli sensörler geliştirilebilir [15]. Metamalzemeler, anten, enerji hasadı ve sinyal emici uygulamalarda kullanılabildiği gibi yine sensör uygulamalarında da ortak olarak kullanılmaktadır [6-12].

Bu çalışmaya benzer olarak metamalzeme tabanlı sensör çalışmaları incelendiğinde, ayrık halka rezonatörlerin dışardan uygulanan elektromanyetik dalga vasıtasıyla arkasında, arasında veya bir kanal içinde yer alan malzemenin dielektrik özelliklerinin değişmesi sonucu, bu değişimin rezonans frekansının değişmesi ile algılandığı görülmektedir. Bu çalışmalara. [13]' de, dielektrik katsayısı 25 den 75 e yükseldiğinde üzerinde bulunan mikroakışkan kanal ile rezonans frekansını 150MHz kaydıran çalışmayı, Methanol ve ethanol gibi alkol türevlerini algılamaya yönelik olarak hazırlanan ve kalite faktörü 28 olan [14]' deki çalışmayı, ve 3 ayrı sensör çalışmasının simülasyon ve deneysel olarak gerçekleştirildiği ve bunun sonucunda 200MHz' lik bir frekans kaymasının elde edildiği[15] çalışmaları örnek olarak verebiliriz.

Metamalzeme temelli çalışmalar dielektrik sabiti üzerindeki değişmeleri algılayabildiği gibi sıcaklık, nem, basınç gibi değişimleri ve kanser hücrelerinin tespitinde de kullanılabilir [16-19]. Metamalzemeler kullanılarak gerçekleştirilen bir diğer uygulama, bu çalışmanın da temelini oluşturan gıdaya yönelik olarak geliştirlen sensör uygulamalarıdır. Bunlara örnek olarak zeytinyağı, pamuk yağı gibi yağların karıştırılarak tüketicilerin aldatılmasına yönelik hilelerin tespit edilmesidir [20-21]. Bu çalışmalardaki en önemli sorun algılama hassasiyeti ve kalite faktörü olarak sıralanabilir. Bu problemin çözümü için bu çalışma hazırlanmış olup yüksek hassasiyet ve kalite faktörü gerektiren pek çok uygulamada temel olacağı düşünülmüştür.

Bu çalışmada, yağlı ve yağsız süt arasındaki dielektrik katsayı farkı çok düşük olduğu için çok hassas bir metamalzeme tabanlı sensör çalışmasına ihtiyaç vardır. Bu amaçla 4 tane ayrık dikdörtgen ve ayrık halka rezonatörlerinden oluşan yapı, düşük dielektrik katsayısı bulunan bir alttaş üzerine $180^{\circ}$ farkla yerleştirilmiştir. Bu çalışmadaki bütün tasarım ve yansıma katsayısı ölçümleri için CST Microwave Studio programı kullanılmıştır. Metamalzeme tabanlı sensör uygulamalarında bir diğer önemli ihtiyaç olan kolay kullanım için temeli 2003 yılında geliştirilen ve WR90 dalga kılavuzu ile uyumlu olan bir örnek tutucunun simülasyona arka yüzde yer alan rezonatörlerin hemen arkasına kapton bant ile kapatılarak yerleştirilmesi gereklidir [22]. Bu örnek tutucu simülasyon programı içinde de yer almaktadır. Sensör katmanı içinde yer alan sıvı malzemenin dielektrik özelliklerinin değişimi dışardan TE polarizasyon modu ve vektör network analizörü kullanılarak uygulanan elektromanyetik dalga sonucu rezonans frekansında kayma meydana getirir. Bu kaymalar yine vektör network analizörü kullanılarak en verimli şekilde okunabilir.Yağlı ve yağsız sütün tespitine yönelik olarak hem analog hem de dijital temelli uygun maliyetli hassas sensörler olsa da bu çalışmada halihazırda var olan uygulamalara ek olarak alternatif bir çözüm üretilmiştir. Önerilen çalışmada yağlı ve yağsız sütün dielektrik katsayıları arasındaki farkı rahatlıkla algılayabilecek bir sensör uygulaması sunulmuştur. Çalışmanın akışı şu şekildedir, 2. Bölümde Materyal ve Metot kısımları sunulurken, 3. Bölümde araştırma bulguları sunulmuş, 4. Bölümde ise elde edilen bu bulguların sonuçları ve ek araştırma olanakları sunularak çalışma tamamlanmıştır.

\section{Materyal ve Metot}

\subsection{Tasarım}

Önerilen tasarım X band dalga kılavuzu içerisinde çalışacağı için boyutları hassas olarak ayarlanarak bu sayede en verimli tasarım elde edilmiş ve sıvı gıdaların mikrodalga teknikleri kullanılarak algılanması için son şekli verilerek Şekil 1'de sunulmuştur. Şekilde görüldüğü üzere önerilen tasarım bir ayrık halka rezonatörü içerisine yerleştirilmiş iki ayrık halka rezonatörü ve bir ayrık dikdörtgen rezonatöründen oluşmaktadır. Şekil 1.c 'de görüldüğü üzere önerilen tasarımın ön görüntüsü ile arka görünüsü arasında $180^{\circ}$ fark vardır. Önerilen tasarımda Şekil 1.b’ de görüldüğü üzere arkasında sensör katmanı yer almaktadır. Bu katman içerisine algılaması yapılacak malzeme yerleştirilmektedir. Ölçüm düzeneği X bant waveguide içinde gerçekleştirileceği için buna uygun olarak Şekil 1.d' de görüldüğü üzere sınır değerleri X, Y ve Z eksenlerinde PEC, PEC ve open add space olarak simülasyon programı tercih edilmiştir. Bu tasarım ve simülasyon çalışmaları FIT tabanlı bir simülasyon programı olan CST Microwace Studio programı üzerinde gerçekleştirilmiştir. Bu yazılım on yıldan uzun bir süredir pek çok mikrodalga çalışmasında kullanılmış olup doğruluğu pek çok kez 
ispatlanmıştır. Önerilen tasarım yağlı ve yağsız sütün mikrodalga teknikler kullanılarak algılanmasına yönelik olduğu için ve her iki süte ait bir sonraki bölümde ölçülen dielelektrik sabitlerinin birbirine yakın olması sebebiyle oldukça hassas olması zorunluluktur. Bu hassasiyetin zorunluluğundan dolayı pek çok tasarım ve simülasyonlar yapılmış, örnek tutucudaki malzemenin dielektrik sabitinin değişimini en iyi algılayacak yapı için toplam 4 rezonatör oluşturulmuş, oluşan iç içe yerleştirilmiş diktörtgen ve halka ayrık rezonatörlerden oluşan yapının Arlon DiClad527 üzerine arkalı önlü bakışımsız olarak yerleştirilmiş, bu durumda da algılama hassasiyeti sonucu oluşacak rezonans kaymasının en yüksek olduğu görülmüştür.
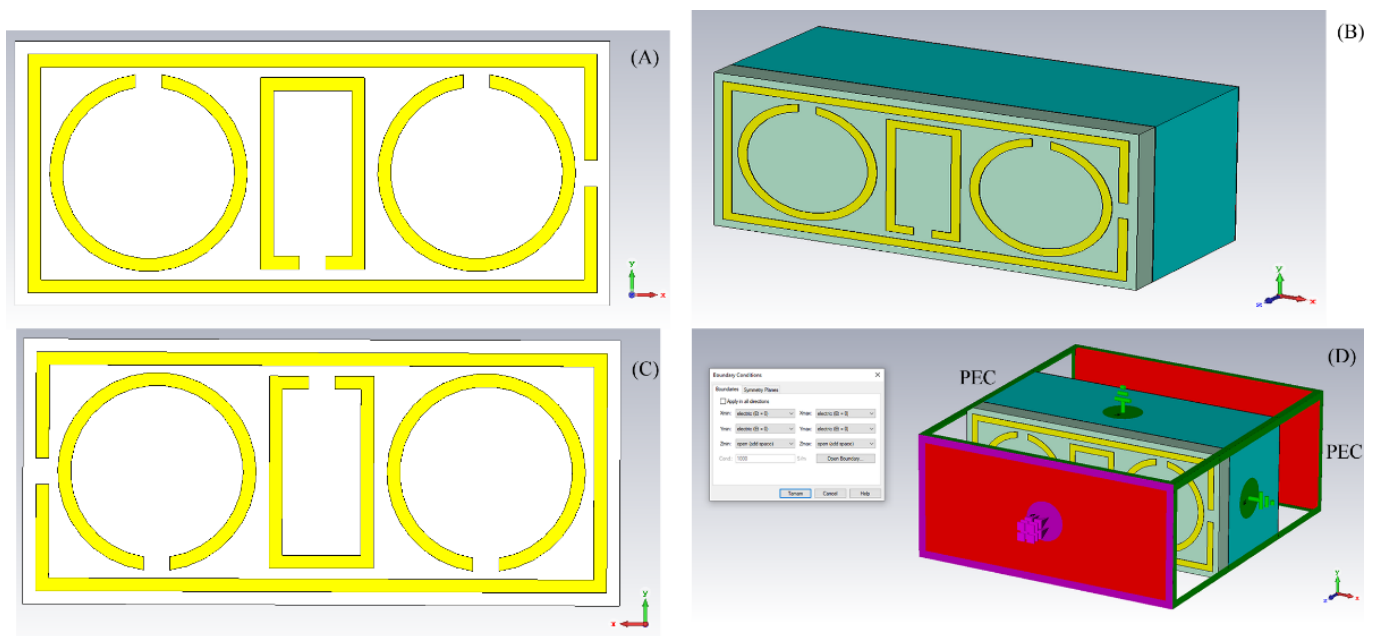

Şekil 1. Önerilen Metamalzeme tabanlı sensör çalışmasına ait tasarım

\subsubsection{Boyutlar ve ölçüm düzeneği}

Önerilen metamalzeme tasarımı boyutları X band yani 8-12 GHz arası dalga kılavuzu içinde çalışacağı için boyutları Şekil 2' de görüldüğü üzere sunulmuştur.

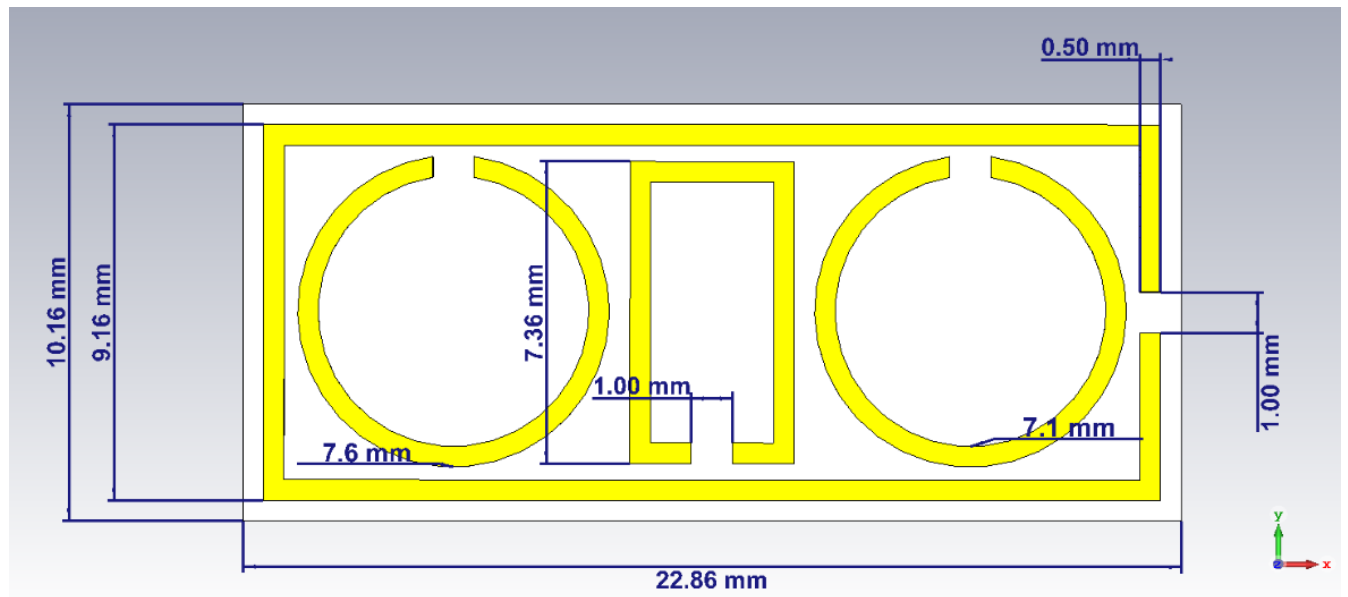

Şekil 2. Önerilen Metamalzeme tabanlı sensör çalışmasına ait ölçülendirme

Önerilen yapı üzerinde bulunan rezonatörler bakır malzemeden imal edilmiş olup iletkenlik katsayısı ve kalınlık değerleri sırasıyla $5.8 \times 10^{6} \mathrm{~S} / \mathrm{m}$ ve $0.035 \mathrm{~mm}$ ' dir. Alttaş olarak Arlon DiClad 527 malzemesi tercih edilmiş, olup bu malzemenin dielektrik katsayısı 2.5 ve kayıp tanjant değeri 0.0022 ' dir. Bu malzemenin seçilmesindeki en önemli etken malzemenin dielektrik katsayısının ve kayıp tanjant değerlerinin çok düşük olması sebebiyle malzeme üzerindeki kayıpların ve kapasitif etkilerin minimize edilerek hassas bir sensör tasarlanması ve bu sayede düşük dielektrik katsayısı değişimlerinin bile rahatlıkla algılanabilmesidir.

Boyutlar belirlenirken hassasiyet kavramının daha iyi anlaşılması için bir sonraki bölümde sunulan yüzey akım dağılımı ve elektrik alan dağlımlarının rezonans frekanslarında incelenmesi çok faydalı olacağı ilgili bölümde sunulmuştur.

\subsection{Dielektrik Katsayılarının Ölçülmesi}

Bu çalışmada dielektrik katsayıları Agilent 42.5 GHz vektör network analizörü ve 85070E dielekrik ölçüm kiti kullanılarak şekil 3' de görüldüğü üzere 8-12 GHz bant aralığında ölçülmüştür. Bu ölçüm kiti Agilent firmasına ait olup, ölçüm öncesinde kullanım kitapçığında tanımlandığı üzere hava, su ve sıcaklık ile kalibrasyon işlemleri gerçekleştirilmiştir. Simülasyon aşamasında doğru 
sonuçların alınması için örnek tutucu kalınlığı $10 \mathrm{~mm}$ olarak belirlenmiş ve bu değer tüm simülasyonlarda sabit tutulmuştur. Örnek tutucunun önünde ve arkasında bulunan açıklıklar kapton film ile kapatılmışırı.

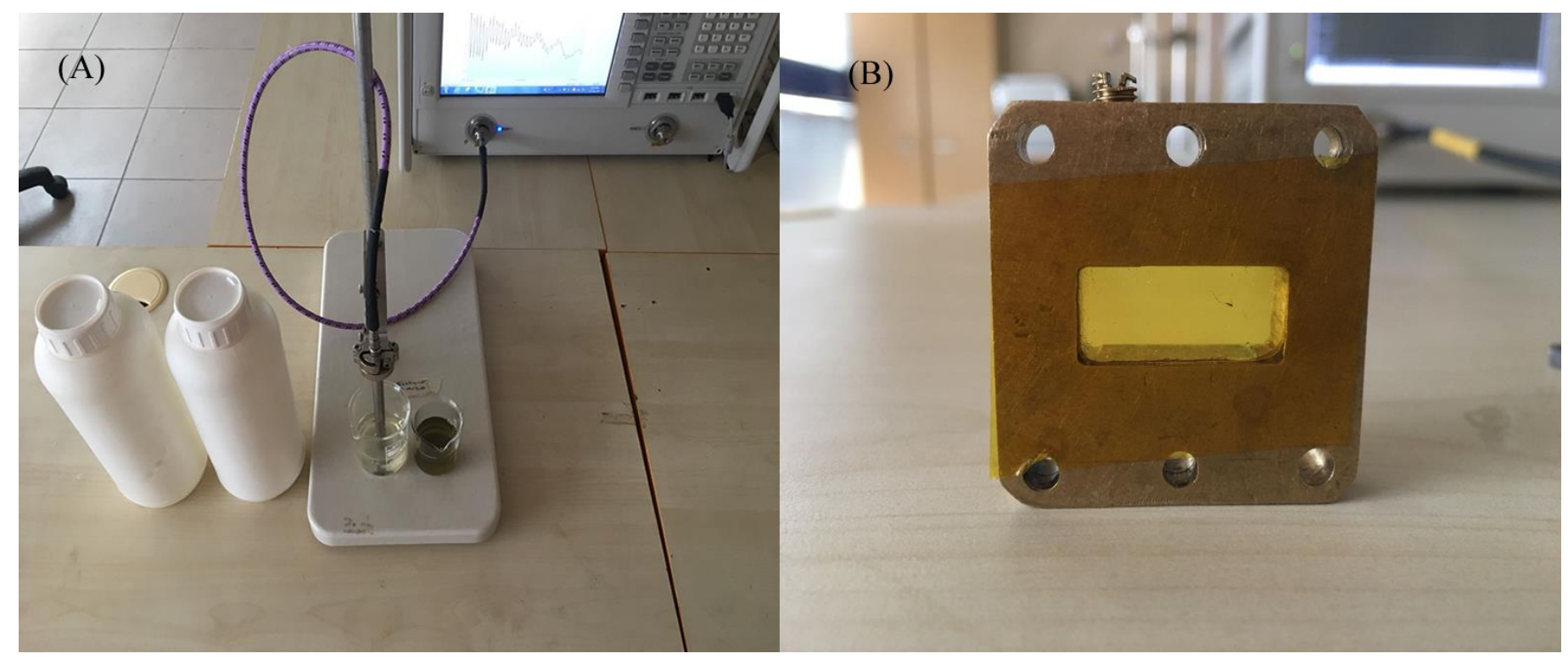

Şekil 3. Yarım yağlı ve tam yağlı sütün dielektrik katsayılarının ölçülmesinde kullanılan açık uçlu dielektrik prob (a) ve yansıma katsayısı ölçümleri için kullanılan örnek tutucu (b).

Komplex dielektrik sabiti $\varepsilon=\varepsilon^{\prime}-j \varepsilon^{\prime \prime}$ formülü ile hesaplanabilir. Buradaki $\varepsilon^{\prime}$ gerçel kısmı gösterirken, $\varepsilon^{\prime \prime}$ sanal kısmı ifade etmektedir. Bu ifadeye dayanarak kayıp tanjant değeri, sanal değerin gerçel değere oranı şeklinde ifade edilebilir. $\left(\delta=\varepsilon^{\prime \prime} / \varepsilon^{\prime}\right)$. Bu çalışmada örnek alınan süt verileri X bantta açık uçlu koaksiyel prob kiti olan Agilent $85070 \mathrm{E}$ ve kalibre edilmiş bir network analizörü kullanılarak ölçülmüştür.

Açık uçlu koaksiyel prob metodu günümüzde dielektrik katsayısı ölçmede kullanılan en popüler tahribatsız tekniklerden birisidir. Genişbant bölgesinde ve yüksek sıcaklıklarda yapılan ölçüm bu çalışmada olduğu gibi açık uçlu koaksiyel prob lar kullanılarak da gerçekleştirilebilir. Bu cihazlar ile gerek yüksek gerek az kayıplı malzemelerin testleri rahatlıkla gerçekleştirilebilir. Dielektrik katsayısı ölçümlerine baktığımızda 3 metot gözümüze çarpacaktır. Bunlar kavite, dalga kılavuzu ve yaklaşım metotları olarak sıralanabilir. Dielektrik sabiti bilinen bir malzeme karakterizasyon için sensör katmanına yerleştirildiğinde, kapasitans değeri artıp azalacaktır [23]. Şekil 1.c de görüldüğü üzere önerilen malzeme ardına yerleştirilen sensör katmanı içindeki bu kapasitans değişimi, bir rezonans kaymasına neden olacak, bu da algılanmak istenen parametreye dönük bir çalışma ortaya çıkaracaktır [24-25]. Bu çalışmada yansıma katsayı parametresi olan $S_{11}$ değeri ile TE polarizasyon modunda yarım yağlı ve yağlı sütlerin tahribatsız olarak mikrodalga teknikleri kullanılarak algılanmasına yönelik bir çalışma geliştirilmiştir. Bu çalışmada kullanılan TE polarizasyon modu, Elektrik alanın dalga yönüne dik olduğu mod olarak tanımlanabilir.

Şekil 4 ve Şekil 5'te Bir süparmarket zincirinde satılan yağsız ve yağlı sütlerin 8-12 GHz aralığında açık uçlu koaksiyel prob kullanılarak ölçülen dielektrik sabitleri görülmektedir. Yağsız sütün dielektrik sabiti beklendiği üzere yağlı süte nazaran daha yüksektir. Distil suyun dielektrik sabitinin 80 olduğu düşünülürse ve yağsız sütte daha fazla su oranı olduğu varsayılırsa ölçülen bu değerler teoriyi doğrulamaktadır. Şekil 5 'te yer alan yağlı süt ile Şekil 4'te yer alan yağsız süt dielektrik sabiti arasında yaklaşık 4 birim fark olmasına rağmen, her ikisinde de kayıp tanjant değerleri çok benzemektedir. 


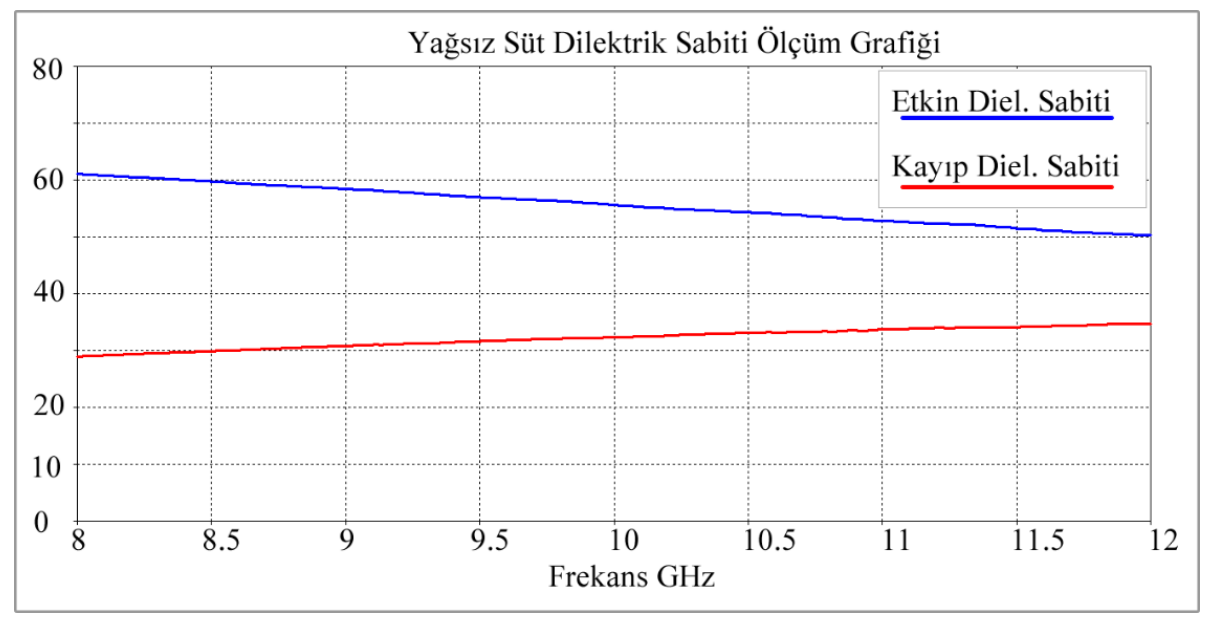

Şekil 4. Bir süparmarket zincirinde satılan yağsız sütün 8-12 GHz aralığında ölçülen Reel (etkin) ve sanal (kayıp) dielektrik sabiti

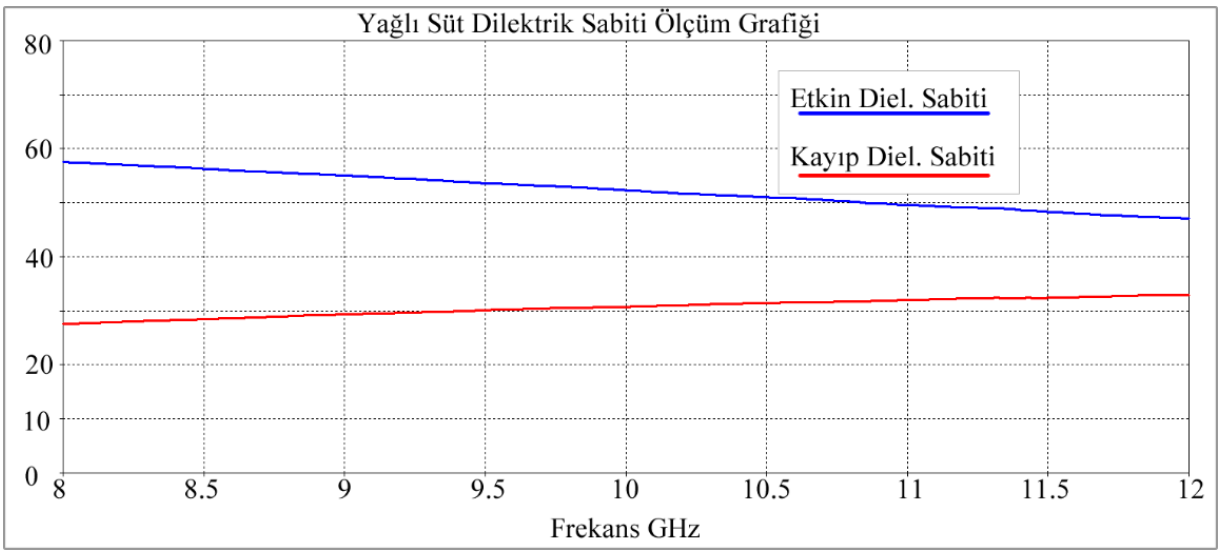

Şekil 5. Bir süparmarket zincirinde satılan yağlı sütün 8-12 GHz aralığında ölçülen Reel (etkin) ve sanal (kayıp) dielektrik sabiti

\section{Araştırma Sonuçları ve Tartışma}

\subsection{Yağlı ve yağsız süte ilişkin yapılan ölçüm sonuçları}

$\mathrm{Bu}$ bölümde önerilen metamalzeme tabanlı sensör yapısının nasıl çalıştığının gösterilmesi için yansıma katsayısı $\mathrm{S}_{11}$ değeri kullanılmıştır. Bir önceki bölümde gösterildiği üzere yağsız ve yağlı sütün dielektrik katsayıları 62 ve 58 'den başlayıp frekansa bağlı olarak azalmaktadır. Bu değerler birbirine çok yakın olduğu için tasarlanan sensörün algılama hassasiyetinin oldukça yüksek olması gerekmektedir. Bu bağlamda Şekil 1'de önerilen ve Şekil 2 de boyutları sunulan yapı ardına yerleştirilen örnek tutucu içine yağsız ve yağlı süte ait dielektrik ölçümlerinin CST Microwave Studio programında oluşturulmasıyla aşağıdaki yansıma katsayısı değeri benzeştirme sonucu alınmıştır.

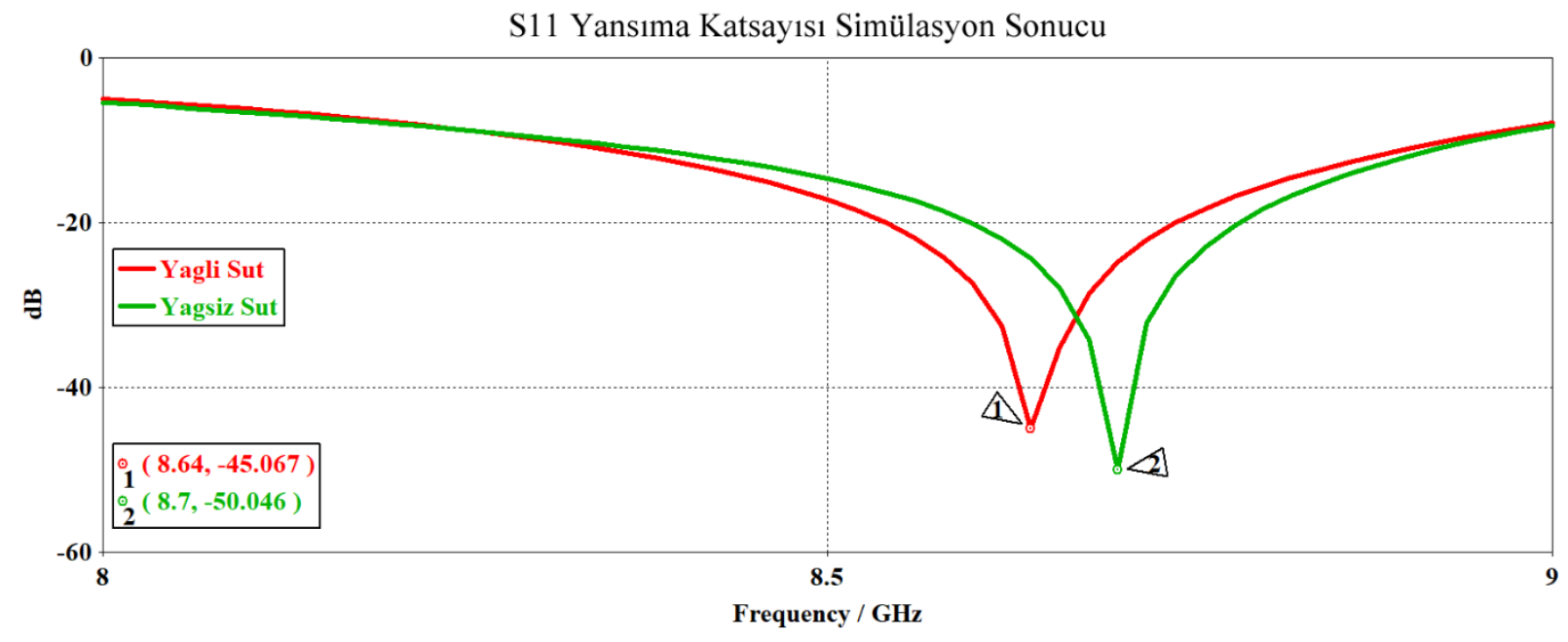

Şekil 6. Bir süpermarkette bulunan yağsız ve yağlı sütün yansıma katsayısı benzetim sonucu 
Şekil 1'de önerilen yapının TE sınır değerleri içerisinde şekil 4 ve şekil 5'de sunulan dielektrik sabitleri kullanılarak yeni bir malzeme tanımlanmasıyla oluşan yansıma katsayısı simülasyon sonucu şekil 6'da görülmektedir. Bu grafikte elde edilen 2 sonuç çok önemlidir. Bunlardan birincisi yağlı ve yağsız süt arasında bulunan 4 birimlik farkın rezonans değerinin $60 \mathrm{MHz}$ gibi frekansı kayması oluşturması çok dikkat çekicidir ve bu durum yapının algılama hassasiyetinin ne kadar yüksek olduğunu göstermektedir. İkinci önemli husus ise önerilen yapının kullanılmasıyla ortaya çıan kalite faktörüdür ki bu değer en küçük 288 olarak ölçülmüştür.

Önerilen yapının daha iyi anlaşılması için yüzey akım dağılımı simülasyon grafiği CST Microwave Studio programı kullanılarak 8.7 GHz belirlenmiş ve Şekil 7' de sunulmuştur.

Şekil 7' de görüldüğü üzere yüzey akım dağılımları rezonatörler üzerinde yoğunlaşmakta ayrık kısımlara geldikçe azalmaktadır. Özellikle ortada yer alan rezonatör üzerindeki yüzey akım dağılımı oldukça fazladır. Yüzeyde görülen paralel ve antiparalel akım dağılımları uygulanan elektromanyetik alana karşı metamalzemenin oluşturduğu elektrik alan ve bu alana karş1 oluşan manyetik alandan kaynaklanmaktadır.Tasarımın alt ve üst bölgelerinde bu durum belirgin bir şekilde görülmektedir.

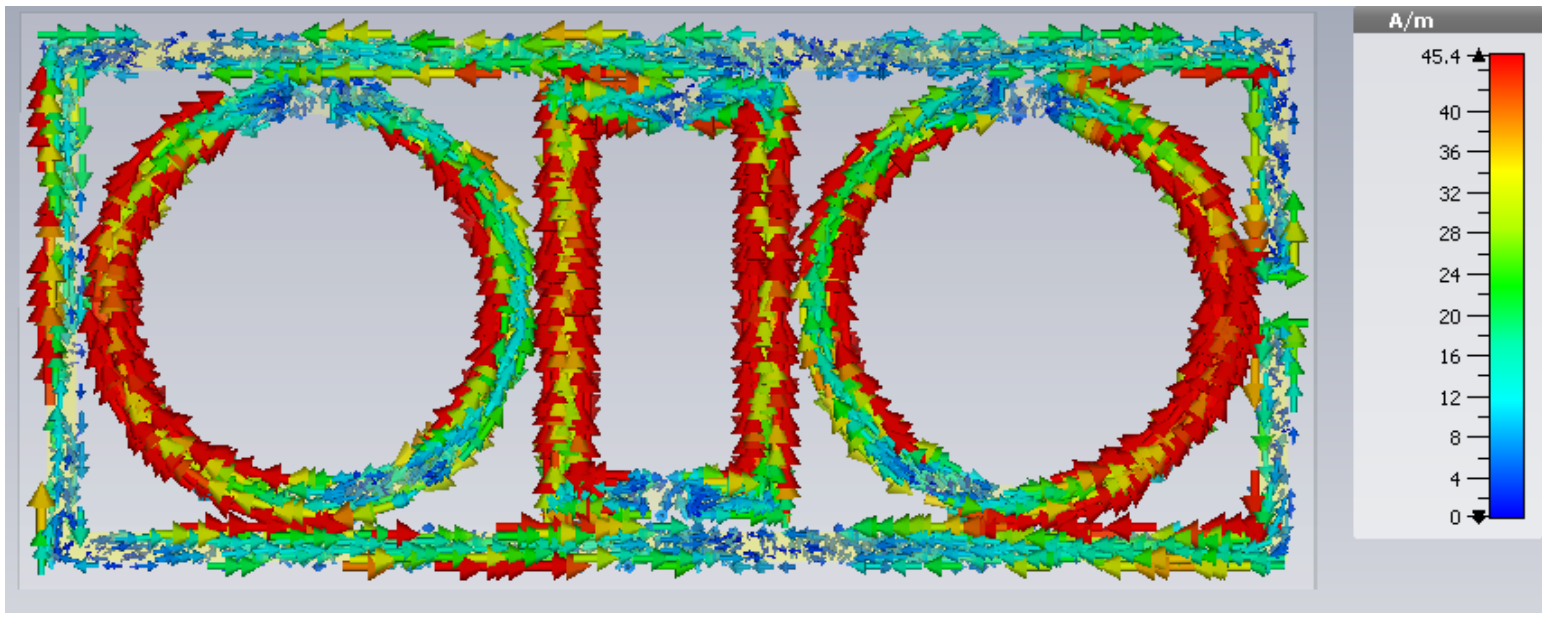

Şekil 7. Önerilen metamalzeme tabanlı sensör çalışmasının yüzey akım dağılım simülasyon grafiği

Bu bulgulara dayanarak Şekil 6'da görülen rezonans kayması

$$
f_{0}=\frac{1}{2 \pi \sqrt{L C}}
$$

Formülü ile açıklanabilir. Bu formülde görüldüğü üzere rezonans frekansı kapasitans değeri ile ters orantılıdır yani kapasitans değeri rezonans değerini geriye doğru çekecektir. Yansıma katsayısı ölçümlerine genel olarak bakıldığında dielektrik değeri arttığında oluşacak kapasitans değeri olumlu olarak etkilenip yükselecektir, bunun sonucunda iletim katsayısı değeri düşerken yansıma katsayısı yani bu çalışmada kullanılan $S_{11}$ parametresi yükselecektir. Şekil 6' ya bakıldığında tam olarak da gerçekleşen budur [25].

\section{Sonuç}

$\mathrm{Bu}$ çalışmada 8-12 GHz aralığında çalışacak Metamalzeme tabanlı bir sensör çalışması TE polarizasyon modunda gerçekleştirilmiştir. Önerilen yapı üzerinde ön yüzünde 4 adet ayrık dikdörtgen ve ayrık halka tabanlı rezonatör kullanılmış arka yüzünde ise ön yüzde kullanılan rezonatörlerin açısı $180^{\circ}$ değiştirilmiştir. Yapının arkasına $10 \mathrm{~mm}$ kalınlığında WR90 dalga klavuzu ile uyumlu boyutlarda $10 \mathrm{~mm}$ kalınlığında bir örnek tutucu yerleştirilerek test edilecek malzemenin bunun içine yerleştirilmesi amaçlanmıştır. Deneysel çalışma olarak süpermarketlerde bulunan yağlı ve yağsız süt örnek olarak alınmış ve bu sütlerin dielektrik katsayıları 85070E açık uçlu dielektrik prob kit ve vektör network analizörü kullanılarak ölçülmüştür. Bu ölçümden sonra önerilen yapının boyutları bu dielektrik değerlerinde en yüksek frekans kayması ve kalite faktörünü verecek şekilde optimize edilmiştir. Bu çalışmadan sonra yansıma katsayısı simülasyon ölçümleri CST Microwave Studio programı kullanılarak gerçekleştirilmiş ve $60 \mathrm{MHz}$ lik bir rezonans kayması olduğu görülmüş̧ür. Bu çalışma iki önemli bulguya sahiptir. Bunlardan birincisi bir metamalzeme tabanlı sensörün bir gıda ürünü üzerinde dielektrik değerlerinin birbirine oldukça yakın olmasına rağmen rezonans kayma değerinin $60 \mathrm{MHz}$ çıkması ve ikincisi ise kalite faktörü değerinin de 288 olarak ölçülmesidir. Elde edilen verilerle, önerilen sensör çalışmasının pekçok uygulamada rahatlıklıkla kullanılabileceği öngörülmektedir. Çünkü çoğu metalzeme tabanlı sensör çalışması dielektrik sabiti değişimine dayanmaktadır. Bu geliştirilen uygulamanın yağlı ve yağsız sütü tahribatsız olarak tespit edebileceği, bunun yanında dielektrik katsayı değerleri 40-80 arasında olan tüm malzemelerde ve ensüstriyel, bilimsel, medikal uygulamalarda da kullanılabileceği açık olarak tespit edilmiştir. 


\section{Kaynakça}

1. Lobato-Morales, H., Corona-Chávez, A., Olvera-Cervantes, J. L., Chávez-Pérez, R. A., \& Medina-Monroy, J. L. (2014). Wireless sensing of complex dielectric permittivity of liquids based on the RFID. IEEE Transactions on Microwave Theory and Techniques, 62(9), 2160-2167.

2. Karaaslan, M., \& Bakir, M. (2014). Chiral metamaterial based multifunctional sensor applications. Progress In Electromagnetics Research, 149, 55-67.

3. Liu, C., \& Tong, F. (2015). An SIW resonator sensor for liquid permittivity measurements at C band. IEEE Microwave and Wireless Components Letters, 25(11), 751-753.

4. Bakir, M., Karaaslan, M., Dincer, F., Akgol, O., \& Sabah, C. (2016). Electromagnetic energy harvesting and density sensor application based on perfect metamaterial absorber. International Journal of Modern Physics B, 30(20), 1650133.

5. Ebrahimi, A., Withayachumnankul, W., Al-Sarawi, S., \& Abbott, D. (2013). High-sensitivity metamaterial-inspired sensor for microfluidic dielectric characterization. IEEE Sensors Journal, 14(5), 1345-1351.

6. Shrekenhamer, D., Chen, W. C., \& Padilla, W. J. (2013). Liquid crystal tunable metamaterial absorber. Physical review letters, $110(17), 177403$

7. Mrnka, M., Vasina, P., Kufa, M., Hebelka, V., \& Raida, Z. (2016). The RF energy harvesting antennas operating in commercially deployed frequency bands: a comparative study. International Journal of Antennas and Propagation, 2016.

8. Almoneef, T., \& Ramahi, O. M. (2014). A 3-dimensional stacked metamaterial arrays for electromagnetic energy harvesting. Progress In Electromagnetics Research, 146, 109-115.

9. Schueler, M., Mandel, C., Puentes, M., \& Jakoby, R. (2012). Metamaterial inspired microwave sensors. IEEE Microwave Magazine, 13(2), 57-68.

10. Vora, A., Gwamuri, J., Pala, N., Kulkarni, A., Pearce, J. M., \& Güney, D. Ö. (2014). Exchanging ohmic losses in metamaterial absorbers with useful optical absorption for photovoltaics. Scientific reports, 4, 4901.

11. Bakır, M., Karaaslan, M., Dincer, F., Delihacioglu, K., \& Sabah, C. (2016). Tunable perfect metamaterial absorber and sensor applications. Journal of Materials Science: Materials in Electronics, 27(11), 12091-12099.

12. Bakır, M., Karaaslan, M., Altıntaş, O., Bagmancı, M., Akdogan, V., \& Temurtaş, F. (2018). Tunable energy harvesting on UHF bands especially for GSM frequencies. International Journal of Microwave and Wireless Technologies, 10(1), 67-76.

13. Ebrahimi, A., Withayachumnankul, W., Al-Sarawi, S., \& Abbott, D. (2013). High-sensitivity metamaterial-inspired sensor for microfluidic dielectric characterization. IEEE Sensors Journal, 14(5), 1345-1351.

14. Abduljabar, A. A., Rowe, D. J., Porch, A., \& Barrow, D. A. (2014). Novel microwave microfluidic sensor using a microstrip splitring resonator. IEEE Transactions on Microwave Theory and Techniques, 62(3), 679-688.

15. Bakir, M. (2017). Electromagnetic-based microfluidic sensor applications. Journal of the electrochemical society, 164(9), B488B494.

16. Altintas, O., Aksoy, M., Akgol, O., Unal, E., Karaaslan, M., \& Sabah, C. (2017). Fluid, strain and rotation sensing applications by using metamaterial based sensor. Journal of The Electrochemical Society, 164(12), B567-B573.

17. Bakır, M., Karaaslan, M., Unal, E., Karadag, F., Alkurt, F. Ö., Altıntaş, O., ... \& Sabah, C. (2018). Microfluidic and fuel adulteration sensing by using chiral metamaterial sensor. Journal of The Electrochemical Society, 165(11), B475-B483.

18. Shih, K., Pitchappa, P., Manjappa, M., Ho, C. P., Singh, R., \& Lee, C. (2017). Microfluidic metamaterial sensor: Selective trapping and remote sensing of microparticles. Journal of Applied Physics, 121(2), 023102.

19. Bernasconi, R., Credi, C., Natale, G., Tironi, M., Cuneo, F., Levi, M., \& Magagnin, L. (2016). Electroless Metallization of Stereolithographic Photocurable Resins for 3D Printing. ECS Transactions, 72(21), 9.

20. Su, L., Mata-Contreras, J., Vélez, P., Fernández-Prieto, A., \& Martín, F. (2018). Analytical method to estimate the complex permittivity of oil samples. Sensors, 18(4), 984

21. Zhang, X., Ruan, C., \& Chen, K. (2019). High-sensitivity microwave sensor for liquid characterization using a complementary circular spiral resonator. Sensors, 19(4), 787.

22. Afsar, Y. W. (2003). Measurement of complex permittivity of liquids using waveguide techniques. Progress In Electromagnetics Research, 42, 131-142.

23. Ebrahimi, A., Withayachumnankul, W., Al-Sarawi, S., \& Abbott, D. (2013). High-sensitivity metamaterial-inspired sensor for microfluidic dielectric characterization. IEEE Sensors Journal, 14(5), 1345-1351.

24. Jafari, F. S., \& Ahmadi-Shokouh, J. (2018). Frequency-selective surface to determine permittivity of industrial oil and effect of nanoparticle addition in x-band. Journal of Electronic Materials, 47(2), 1397-1404.

25. Withayachumnankul, W., Jaruwongrungsee, K., Tuantranont, A., Fumeaux, C., \& Abbott, D. (2013). Metamaterial-based microfluidic sensor for dielectric characterization. Sensors and Actuators A: Physical, 189, 233-237. 